\title{
Pregnancy in a quadriplegic patient treated with continuous intrathecal baclofen infusion to manage her severe spasticity. Case report.
}

\author{
E M Delhaas MD, ${ }^{1} \mathrm{~J}$ Verhagen $\mathrm{MD}^{2}$ \\ Departments of ${ }^{1}$ Anaesthesiology, ${ }^{2}$ Gynaecology and Obstetrics, Sophia Hospital, PO \\ Box 10400, 8000 GK Zwolle, The Netherlands.
}

\begin{abstract}
A report on pregnancy in a quadriplegic patient treated with a high dose of $1000 \mathrm{mcg} / 24 \mathrm{~h}$ continuous intrathecal baclofen infusion using an implanted drug delivery system (Synchromed $^{(\mathrm{R})}$, Medtronic, USA). Spasticity could be managed up to the 35 th week of gestation. However, uterine contractions evoke enormous spastic symptoms which we, even with maximum values of the spasticity scales, could not classify. The recurrence of spasticity was associated with autonomic dysregulation. With continuous epidurally infused bupivacaine $(11.25 \mathrm{mg} / \mathrm{h})$ adequate relaxation could be reached and gestation was terminated by a primary caesarean section. A healthy girl was born (2040 g, Apgar 9 and $10)$.
\end{abstract}

Key words: spasticity; intrathecal baclofen; spinal cord injury; pregnancy.

Gestation need not be discouraged in patients with spinal cord lesions. ${ }^{1,2}$ As a result pregnancy may now be possible for previously spastic women, in whom the seriously disabling spastic features are suppressed by intrathecal baclofen infusion. ${ }^{3}$ We are reporting a pregnancy in a quadriplegic patient treated with continuous intrathecal baclofen infusion to manage her severe spasticity.

\section{Case report}

The intractable spasticity (maximum values of Ashworth- $(=5)$, spasm- $(=4)$ and clonus scale $(=5))$ in a 29 year old quadriplegic (since 1983) patient, gravida 1 , para 0 , with an incomplete cervical C6-7 spinal cord lesion following discitis after discography, was successfully treated with a high dose of $1000 \mathrm{mcg} / 24 \mathrm{~h}$ continuous intrathecal baclofen administration using an implanted drug delivery system $\left(\right.$ Synchromed $^{(\mathrm{R})}$, Medtronic, USA). The prolonged extended improvement of her disability (spasticity scales respectively 1,0 and 1) and the lack of side effects from the intrathecal baclofen therapy were the reasons for the spouses' wish for children. After 15 months of baclofen treatment she became pregnant after ovulation stimulation with clomiphene. With a gradual increase of the intrathecal baclofen dose $(1100 \mathrm{mcg} / 24 \mathrm{~h})$ spasticity could be fairly well controlled. She was hospitalised in the 32 nd week. At that time premature uterine contractions and concomitant mild spastic features arose (spasticity scales 1,4 and 2) which again could be controlled by a further increase of the baclofen $(1200 \mathrm{mcg} / 24 \mathrm{~h})$. Uterine contractions were suppressed by an intravenous infusion of fenoterol $(1.4 \mathrm{mg} / 24 \mathrm{~h})$. Cardiotocogram, placental hormones, blood flow velocity in the umbilical cord and ultrasound examination were normal. However in the 35th week spasticity could no longer be controlled by dose increments (up to $1400 \mathrm{mcg} / 24 \mathrm{~h}$ ). Even with maximum values of the spasticity scales we could not classify the evoked spastic symptoms. Continuous muscular contractions of the legs, severe flexor and abdominal muscle spasms, piloerection, sweating, headache, fluctuations of blood pressure (120/85 to $180 / 110)$ and heart rate ( 70 to 110 beats $/ \mathrm{min}$ ) related to the severe paroxysmal abdominal muscle contractions occurred. ${ }^{4}$ With continuous epidurally infused bupivacaine $(11.25 \mathrm{mg} / \mathrm{h})^{1,5}$ adequate relaxation could be reached. The severe spasticity associated with symptoms of autonomic dysregulation $^{1,2,4-9}$ was the reason for considering 
termination of gestation. After assessment of foetal pulmonary maturity (amniotic fluid lecithin/sphingomyelin (L/S) ratio $>2$ ), we carried out a primary caesarean section under epidural bupivacaine anaesthesia. A healthy girl was born (2040 g, Apgar 9 and $10)$. Postoperatively spasticity could again be effectively managed.

\section{Discussion}

With the new treatment of continuous intrathecal baclofen infusion, gestation is now possible in patients with a high spinal cord lesion associated with severe spasticity. However, our patient demonstrated that painful visceral stimulation below the le- sion, like mild uterine contractions, evokes enormous spastic symptoms, as well as potentially life threating autonomic dysregulation ${ }^{1,9}$, which were insufficiently controlled by intrathecal baclofen infusion. The fact that postoperatively spasticity was again easily managed indicates that recurrence of the spastic symptoms was caused by breakthrough in the intrathecal baclofen therapy.

\section{Acknowledgement}

We wish to thank WA Kaasjager MD PhD, HB Rethmeier MD and $\mathrm{J}$ Wildschut MD $\mathrm{PhD}$ of the Department of Gynaecology and Obstetrics for their help and Ciba-Geigy Pharmaceuticals for provision of the baclofen.

\section{References}

1 McGregor JA, Meeuwsen J (1985) Autonomic hyperreflexia: a mortal danger for spinal cord-damaged women in labor. Am J Obstet Gynecol 151: 330-333.

2 Verduyn WH (1986) Spinal cord injured women, pregnancy and delivery. Paraplegia 24: 231-240.

3 Penn RD, Kroin JS (1984) Intrathecal baclofen alleviates spinal cord spasticity. Lancet i: 1078.

4 Comarr AE (1975) Observations on menstruation and pregnancy among female spinal cord injury patients. Paraplegia 13: 263-271.

5 Wanner MB, Rageth CJ, Zach GA (1987) Pregnancy and autonomic hyperreflexia in patients with spinal cord lesions. Paraplegia 25: 482-490.

6 Bérard EJJ (1989) The sexuality of spinal cord injured women: physiology and pathophysiology. A review. Paraplegia 27: 99-112.

7 Guttmann L, Frankel H, Paeslack V (1965) Cardiac irregularities during labour in paraplegic women. Paraplegia 3: 144-151.

8 Catanzarite VA, Ferguson JE, Weinstein C, Belton SR (1986) Preterm labor in the quadriplegic parturient. Am J Perinatol 3: 115-118.

9 Abouleish E (1980) Hypertension in a paraplegic parturient. Anesthesiology 53: 348-349. 